\title{
Duration of diabetes as an important risk factor of microalbuminuria in type 2 diabetes
}

\author{
Vitasari Indriani*, Tri Lestari*, and Vidya Dewantari**
}

\begin{abstract}
*Clinical Pathology Department, Medical Faculty,

Jenderal Soedirman University

**Bioethics and Humaniora

Department, Medical Faculty,

Jenderal Soedirman University

\section{Correspondence:}

Vitasari Indriani

Clinical Pathology Department,

Medical Faculty,

Jenderal Soedirman University

Gumbreg Street No 1, Purwokerto,

Central Java Indonesia

Email: vita.indriani@gmail.com

ORCID ID: 0000- 0001-8563-1781

BACKGROUND

Microalbuminuria is the earliest evidence of diabetic nephropathy and a major predictor of end stage renal disease (ESRD). The objective of the study was to determine the influence of several risk factors on the presence of microalbuminuria in type 2 diabetics.

\section{METHODS}

This observational cross-sectional study was done on 73 patients with type 2 diabetes, who attended the Prolanis program in Primary Health Care from May to November 2018. Detailed medical histories including duration of diabetes and relevant clinical examinations including fasting blood sugar (FBS), post-prandial blood sugar (PPBS), HbA1c, serum creatinine, blood urea and urinary microalbumin were recorded for each patient. A multiple regression analysis was used to analyze the data. The analysis was assessed at $5 \%$ level of significance.
\end{abstract}

Date of first submission, December 11, 2018

Date of final revised submission, March 31,2020

Date of acceptance, April 1, 2020

This open access article is distributed under a Creative Commons AttributionNon Commercial-Share Alike 4.0 International License

Cite this article as: Indriani $\mathrm{V}$, Lestari T, Dewantari V. Duration of diabetes as an important risk factor of microalbuminuria in type 2 diabetes. Univ Med 2020;39:426. doi: $10.18051 /$ UnivMed.2020. v38.42-46.

\section{RESULTS}

Mean age of study population was $51.89 \pm 6.78$ years with female preponderance $(51.1 \%)$. Mean FBS, PPBS, HbA1c, duration of diabetes, systolic blood pressure, microalbuminuria and serum creatinine was 182.51 $\pm 74.63 \mathrm{mg} / \mathrm{dL}, 186.25 \pm 26.72 \mathrm{mg} / \mathrm{dL}, 8.8 \pm 1.83 \%, 9.37 \pm 5.96$ years, 118.44 $\pm 4.13 \mathrm{mmHg}, 30.32 \pm 3.2 \mathrm{mg} /$ day and $1.33 \pm 0.64 \mathrm{mg} / \mathrm{dL}$ respectively. Duration of diabetes and $\mathrm{HbA} 1 \mathrm{c}$ were positively correlated with microalbuminuria $(\beta=0.052 ;$ Beta $=0.367 ; \mathrm{p}<0.001$ and $\beta=0.058 ;$ Beta $=0.363 ; \mathrm{p}<0.001)$ respectively.

\section{CONCLUSIONS}

Duration of diabetes was the most important risk factor of microalbuminuria in type 2 diabetes patients. Therefore microalbuminuria can predict diabetic nephropathy earlier, as a warning to prevent further worsening of diabetic complications.

Keywords: Diabetic nephropathy, HbAlc, microalbuminuria, type 2 diabetes 


\section{INTRODUCTION}

Diabetes mellitus (DM) is a metabolic disorder characterized by persistent hyperglycemia resulting from defects in insulin secretion, action or both. Chronic hyperglycemia initiates microvascular complications including nephropathy, retinopathy and neuropathy. Poor glycemic control plays an important role in the development and progression of nephropathy with associated increase in morbidity and mortality. ${ }^{(1)}$

The presence of albuminuria is an indicator of renal impairment. Microalbuminuria, defined as an elevation of urinary albumin excretion in the range of $30-300 \mathrm{mg} / 24 \mathrm{hr}$ or $20-200 \mu \mathrm{g} / \mathrm{min}$, is associated with adverse health outcomes in adults. (2) Microalbuminuria is strongly associated with endothelial dysfunction, which increases the risk of nephropathy and other complications in diabetes. ${ }^{(3)}$

Glycosylated hemoglobin (HbAlc) has been used as a measure of long-term glycemic control and has proven to be a more accurate and stable measure than fasting blood sugar level (FBS) and post-prandial blood sugar (PPBS). ${ }^{(4)}$ An annual assessment of kidney function by the determination of urinary albumin excretion and of $\mathrm{HbAlc}$ for glycemic control is recommended for patients with diabetes. ${ }^{(5)}$

Chen et al. ${ }^{(6)}$ identified the relationships of high normal albuminuria and glycemic control on microalbuminuria development among type 2 diabetes patients. Previous studies had revealed that various factors such as glucose level ${ }^{(7)}$, glycemic variability ${ }^{(8)}$ and insulin resistance impact development of microalbuminuria in type 2 diabetes. ${ }^{(9)}$ In the present study the population comprised patients with type 2 diabetes mellitus attending the primary health care system under the chronic disease management program (Prolanis). Only FBS and PPBS were checked every month. Since increased risk of nephropathy must be detected earlier, further correlations between the various factors were investigated in our study.

The present study was performed to determine the relationship of $\mathrm{HbAlc}$ with microalbuminuria by considering the following factors: age, gender, FBS, PPBS, blood pressure, blood urea level, serum creatinine level and duration of diabetes.

\section{METHODS}

\section{Research design}

An observational study of cross-sectional design was done in the Prolanis program in Primary Health Care (FKTP Klinik Tanjung Purwokerto) from May 2018 to November 2018.

\section{Research subjects}

An observational study and a randomized sample of 73 clinically diagnosed cases of type 2 diabetes aged $>18$ years. Based on a previous finding that serum creatinine was positively correlated with microalbuminuria $(\mathrm{r}=0.33)^{(10)}$ and using $\alpha=0.05, \beta=0.20$, and drop-out rate of $20 \%$, the total calculated sample was 73 subjects Thirty seven female and thirty six male clinically diagnosed cases of type 2 diabetes who attended the Prolanis program were included. Patients suffering from acute and chronic inflammatory conditions, pre-existing chronic kidney disease, glomerulonephritis, nephrotic syndrome, smokers, alcoholics, patients on nephrotoxic drugs, and primary hypertensives were excluded from the study. Medical records of the patients comprising age, gender, duration of diabetes, glycated hemoglobin, blood urea, serum creatinine, and urinary microalbumin levels were analyzed for each patient.

\section{Laboratory analysis}

Blood samples were collected after 10-12h of fasting. Taking all aseptic and antiseptic precautions, $5 \mathrm{~mL}$ of blood was drawn from the antecubital vein and a 24-hour urine sample was collected in a sterilized container. The following measurements were done: FBS, PPBS, blood urea, serum creatinine by enzymatic method (Dimension EXL 200), HbAlc measured by Clover A1c Self with boronate affinity method, and microalbuminuria by fluorescent immunoassay (FIA) method (Ichroma Microalbumin).

\section{Statistical analysis}

All analyses were performed using IBM SPSS version 20. Results on continuous measurements were presented as mean \pm standard deviation (SD) and results on categorical measurements as numbers (\%). A determine the relationship between several risk factors and microalbuminuria. The analysis was assessed at 5\% level of significance. 
Table 1. Distribution of characteristics and laboratory parameters of patients with type 2 diabetes

\begin{tabular}{lc}
\hline \multicolumn{1}{c}{ Parameter } & $\begin{array}{c}\text { Diabetic type 2 } \\
\text { patients (n=73) }\end{array}$ \\
\hline Age (yr) & $51.89 \pm 6.78$ \\
$\begin{array}{l}\text { Gender (\%) } \\
\quad \text { Male }\end{array}$ & $36(48.9 \%)$ \\
$\quad$ Female & $37(51.1 \%)$ \\
Fasting blood sugar (mg/dL) & $182.51 \pm 74.63$ \\
Post prandial blood sugar & $186.25 \pm 26.72$ \\
(mg/dL) & \\
Systolic blood pressure & $118.44 \pm 4.13$ \\
(mmHg) & \\
Diastolic blood pressure & $84.44 \pm 19.25$ \\
(mmHg) & \\
HbA1c (\%) & $8.8 \pm 1.83$ \\
Microalbuminuria (mg/day) & $30.32 \pm 3.2$ \\
Serum creatinine (mg/dL) & $1.33 \pm 0.64$ \\
Blood urea (mg/dL) & $43.2 \pm 15.0$ \\
Duration of diabetes (yr) & $9.37 \pm 5.96$ \\
\hline *Data presented as Mean + SD, except age in $\%$
\end{tabular}

\section{Ethical clearance}

The study has been approved by the Health Research Ethics Commission (Komisi Etik Penelitian Kesehatan, KEPK), Medical Faculty, Jenderal Soedirman University, under no. 1792/KEPK/IV/2018. All subjects were informed of the study protocol in written and verbalform and provided informed consent.

\section{RESULTS}

The mean age of the subjects was $51.89 \pm$ 6.78 years, and most subjects were female $(51.1 \%)$. The mean serum creatinine was $1.33 \pm$ $0.64 \mathrm{mg} / \mathrm{dL}$, mean duration of diabetes was 9.37 \pm 5.96 years, mean $\mathrm{HbA} 1 \mathrm{c}$ was $8.8 \pm 1.83$ (Table 1).

\section{DISCUSSION}

Our study showed that duration of diabetes was the most potential risk factor of microalbuminuria. A similar result was shown by a study involving 227 subjects with type 2 DM in Kathmandu, in that diabetes duration was the most important risk factor for the development of microalbuminuria in diabetes. (11) Another study showed consistent results in that duration of diabetes was an independent risk factor for microalbuminuria. ${ }^{(12)}$ Microalbuminuria is the most sensitive marker of early recognition of diabetic nephropathy. Monitoring microalbuminuria and other risk factors associated with this condition is important to take measures to prevent or postpone overt nephropathy. ${ }^{(13)}$ More importantly, tight glycemic control with insulin during the microalbuminuria stage has been shown to prevent the development of overt diabetic nephropathy. ${ }^{(14)}$

The level of HbA1c has been widely accepted as an indicator of mean daily blood glucose concentration over the preceding 8-12 weeks. Our study also found a significant relationship between $\mathrm{HbA} 1 \mathrm{c}$ and microalbuminuria. Bhoomika et al. ${ }^{(15)}$ studied risk factors for microalbuminuria in type 2 diabetes mellitus patients and reported significantly high $\mathrm{HbA1c}$ levels in patients with microalbuminuria. Another study also highlights that there was a significant correlation between microalbumin levels and $\mathrm{HbAlc}$ in diabetic type 2 subjects. ${ }^{(16)}$ However, another study in Iran did not find a significant association between $\mathrm{HbA} 1 \mathrm{c}$ and microalbuminuria. ${ }^{(12)}$

Table 2. Multiple linear regression analysis of several risk factors and microalbuminuria

\begin{tabular}{lccc}
\hline & $\boldsymbol{\beta}$ & Beta & p value \\
\hline Age (years) & 0.946 & 0.086 & 0.033 \\
Gender & 0.876 & 0.112 & 0.064 \\
Systolic blood pressure (mmHg) & 0.270 & 0.081 & 0.034 \\
Diastolic blood pressure (mmHg) & 0.278 & 0.085 & 0.043 \\
Diabetes duration (years) & 0.052 & 0.367 & $<0.001^{*}$ \\
FBS (mg/dL) & 0.045 & 0.091 & 0.059 \\
PPBS (mg/dL) & 0.48 & 0.086 & 0.033 \\
HbAlc (\%) & 0.058 & 0.363 & $<0.001^{*}$ \\
Blood urea (mg/dL) & 0.054 & 0.087 & 0.059 \\
Serum creatinine (mg/dL) & 0.048 & 0.076 & 0.023 \\
\hline
\end{tabular}

Multiple linear regression showed that diabetes duration was the most potential risk factor of microalbuminuria $(\beta=0.052$; Beta=367; $p<0.001)$ followed by HbA1c level $(\beta=0.058$; Beta $=0.363 ; p<0.001)$ 
Relationship of duration of type 2 diabetes mellitus with microalbuminuria and high $\mathrm{HbAlc}$ level has been reported. Chronic hyperglycemia is responsible for the pathogenesis of diabetic nephropathy. The possible mechanism is that hyperglycemia leads to glycation of virtually all proteins, resulting in the formation of advanced glycation end products. The interaction of advanced glycation end products and their receptors and increased activity of the polyol pathway have been implicated as mediators of increased microvascular permeability, ischemia and angiogenesis. ${ }^{(16)}$

Baig et al. ${ }^{(17)}$ studied 60 patients and concluded that in patients with type 2 diabetes mellitus, long duration of diabetes and poor glycemic control significantly correlated with high level of microalbumin. Another study reported that higher grades of $\mathrm{HbAlc}$ are associated with higher severity of microalbuminuria and so can be used as a marker of good glycemic control. ${ }^{(18)}$

Microalbuminuria usually comes out 5-15 years after the diagnosis of type 2 diabetes mellitus. Combination of glomerular hypertension and glomerular hyperperfusion explains the "hyperfiltration" which occurs in the remaining nephrons. These changes occur in the absence of uremia. In later stages the glomerular filtration rate (GFR) decreases with the appearance of macroproteinuria along with clinical signs of nephropathy and finally leads to end stage renal disease (ESRD). ${ }^{(19)}$ Liu et al. ${ }^{(3)}$ and Kondaveeti et al. ${ }^{(20)}$ also reported that good glycemic control was the strong influencing factor which played a key role in the transition of non-microalbuminuric subjects to microalbuminuric.

Several limitations were encountered in this study. First, the study was not populationbased and only patients who presented at diabetes centers were included. This may have introduced referral bias and it would therefore be difficult to extend our findings to the general population of diabetes patients. Second, we have also not examined the role of $\mathrm{HbAlc}$ variability on microvascular complication development, and we had difficulties in determining the duration of diabetes. Third, the cross-sectional nature of the study design limits the reliability of the observed associations between risk factors and diabetic nephropathy. Because microalbuminuria is widely used as a sensitive risk marker to identify those at risk for renal dysfunction, screening programs should be implemented at an early stage to prevent or postpone end-stage renal disease (ESRD). So, it may be suggested that determination of microalbumin levels in urine is an easy method of screening diabetic patients, especially diabetic patients with long-term diabetes. Further well-designed prospective studies enrolling larger populations are warranted.

\section{CONCLUSIONS}

Duration of diabetes and $\mathrm{HbA} 1$ level were important risk factors of microalbuminuria in patients with type 2 diabetes, with duration of diabetes being the most important.

\section{CONFLICT OF INTEREST}

There is no conflict of interest in their report.

\section{ACKNOWLEDGEMENT}

Special thanks are due to Prolanis program in Primary Health Care and Medical Faculty of Jenderal Soedirman University for financial support.

\section{CONTRIBUTORS}

VI was responsible for writing of the article. TL was responsible for submission of the article. VD was the advisor. All authors have read and approved the final manuscript.

\section{REFERENCES}

1. Kumar R, Abbas A, Fausto N, Aster JC, eds. Robbins and Cotron Pathologic basis of disease. 8th ed. Philadelphia: Saunders Elsevier Publishing Division; 2010.

2. Lee JM, Eason A, Nelson C, et al. Screening practices for identifying type 2 diabetes in adolescents. J Adolesc Health 2014;54:139-43.

3. Liu Z, Fu C, Wang W, Xu B. Prevalence of chronic complications of type 2 diabetes mellitus in outpatients - a cross-sectional hospital based survey in urban China. Health Qual Life Outcomes 2010;8:62. doi: 10.1186/ 1477-7525-8-62.

4. Jun M, Perkovic V, Cass A. Intensive glycemic control and renal outcome. Contrib Nephrol 2011;170:196-208. doi: 10.1159/000325664. 
5. Haller H, Ito S, Izzo Jr JL, et al. Olmesartan for the delay or prevention of microalbuminuria in type 2 diabetes. N Engl J Med 2011;364:90717. doi: 10.1056/NEJMoa1007994.

6. Chen WZ, Hung CC, Wen YW, Ning HC, Gau BR, Huang YY. Effect of glycemic control on microalbuminuria development among type 2 diabetes with high-normal albuminuria. Ren Fail 2014; 36: 171-5. DOI: 10.3109/0886022X. 2013.832312.

7. Murussi M, Campagnolo N, Beck MO, Gross JL, Silveiro SP. High-normal levels of albuminuria predict the development of microand macroalbuminuria and increased mortality in Brazilian type 2 diabetic patients: an 8-year follow-up study. Diabet Med 2007;24:1136-42

8. Hsu CC, Chang HY, Huang MC, et al. HbA1c variability is associated with microalbuminuria development in type 2 diabetes: a 7-year prospective cohort study. Diabetologia 2012; 55:3163-72. DOI 10.1007/s00125-012-2700-4.

9. Hsu CC, Chang HY, Huang MC, et al. Association between insulin resistance and development of microalbuminuria in type 2 diabetes: a prospective cohort study. Diabetes Care. 2011;34:982-7. doi: 10.2337/dc10-1718.

10. Gupta M, Singh JP. Correlation of microalbuminuria with glycosylated haemoglobin in patients of diabetes having nephropathy. Int J Adv Med 2017;4:805-8. DOI: http://dx.doi.org/10.18203/2349-3933. ijam20172276.

11. Thakur SK, Dhakal SP, Parajuli S, Sah AK, Nepal SP, Paudel BD. Microalbuminuria and its risk factors in type 2 diabetic patients. J Nepal Health Res Counc 2019;17:61-5. doi: 10.33314/ jnhrc. 1620.

12. Ansar MM, Shahrokhirad R, Lebady MK. Risk factors of microalbuminuria and macroalbuminuria in type 2 diabetic patients in
North of Iran - Rasht. Nephrourol Mon 2017; 9:e40031.doi: 10.5812/numonthly.40031.

13. Pasko N, Toti F, Strakosha A, et al. Prevalence of microalbuminuria and risk factor analysis in type 2 diabetes patients in Albania: the need for accurate and early diagnosis of diabetic nephropathy. Hippokratia 2013;17: 337-41.

14. Parchwani DN, Upadhyah AA. Diabetic nephropathy: progression and pathophysiology. Int J Med Sci Public Health 2012; 4: 7-11. DOI: 10.5455/ijmsph.2012.1.59-70.

15. Dadhania BP, Aravat AH, Dhruva GA. Study of microalbuminuria in type 2 diabetes patients as a marker of morbidity (a study of 100 cases in Rajkot City). JBAR 2012;3:763-6.

16. Kundu D, Roy A, Mandal T, Bandyopadhyay U, Ghosh E, Ray D. Relation of microalbuminuria to glycosylated hemoglobin and duration of type 2 diabetes. Niger J Clin Pract 2013;16:216-20.

17. Baig JA, Asif N, Sarfaraz A, Alam JM. Correlation of microalbuminuria with glycosylated hemoglobin (Hbalc) and duration of type 2 diabetes mellitus (T2DM) in male and female patients. Middle-East J Sci Res. 2016; 24:2900-3

18. Bagzai A, Bagzai DS. Correlation between severity of microalbuminuria with $\mathrm{HbA} 1 \mathrm{c}$ in type II diabetic patients. JMSCR2019;7:310-3.

19. Sabatini S, Kurtzman NA. Role of hyperfiltration in the pathogenesis of diabetic nephropathy. In: Advances in pathogenesis of diabetic nephropathy. New York: Nova Science Publishers, Inc; 2012.p.:1-27.

20. Kondaveeti SB, Kumaraswamy D, Mishra S, Kumar AR, Shaker IA, Evaluation of glycated albumin and microalbuminuria as early risk markers of nephropathy in type 2 diabetes mellitus. J Clin Diagn Res 2013;7: 1280-3. doi: 10.7860/JCDR/2013/5145.3117. 